Research Article

\title{
Neuroprotective Effects of Early Hypothermia Induced by Phenothiazines and DHC in Ischemic Stroke
}

\author{
Yun Han, ${ }^{1,2}$ Xiao-kun Geng $\mathbb{D}^{1,2,3}$ Hangil Lee, ${ }^{3}$ Fengwu Li, ${ }^{1}$ and Yuchuan Ding ${ }^{3,4}$ \\ ${ }^{1}$ Luhe Institute of Neuroscience, Capital Medical University, Beijing, China \\ ${ }^{2}$ Department of Neurology, Luhe Clinical Institute, Capital Medical University, Beijing, China \\ ${ }^{3}$ Department of Neurosurgery, Wayne State University School of Medicine, Detroit, Michigan, USA \\ ${ }^{4}$ Department of Research \& Development Center, John D. Dingell VA Medical Center, Detroit, Michigan, USA \\ Correspondence should be addressed to Xiao-kun Geng; xgeng@ccmu.edu.cn
}

Received 27 May 2020; Revised 11 December 2020; Accepted 31 December 2020; Published 18 January 2021

Academic Editor: Shao-Hsuan Kao

Copyright $\odot 2021$ Yun Han et al. This is an open access article distributed under the Creative Commons Attribution License, which permits unrestricted use, distribution, and reproduction in any medium, provided the original work is properly cited.

\begin{abstract}
Background and Purpose. Studies have shown that interischemia hypothermia is able to reduce the size of myocardial infarctions and improve their clinical outcomes. The present study determined whether interischemia hypothermia induced by the pharmacological approach induced stronger neuroprotection in ischemic brains. Methods. Adult male Sprague Dawley rats were studied in 4 groups: (1) sham; (2) stroke; (3) stroke treated with pharmacological hypothermia before reperfusion (interischemia hypothermia); and (4) stroke treated with pharmacological hypothermia after reperfusion is initiated (inter-reperfusion hypothermia). The combination of chlorpromazine and promethazine with dihydrocapsaicin (DHC) was used to induce hypothermia. To compare the neuroprotective effects of drug-induced hypothermia between the interischemia and inter-reperfusion groups, brain damage was evaluated using infarct volume and neurological deficits at $24 \mathrm{~h}$ reperfusion. In addition, mRNA expressions of NADPH oxidase (NOX) subunits ( $\mathrm{gp} 91^{\text {phox }}, \mathrm{p} 67^{\text {phox }}, \mathrm{p} 47^{\text {phox }}$, and $\mathrm{p} 22^{\text {phox }}$ ) and glucose transporter subtypes (GLUT1 and GLUT3) were determined by real-time PCR at 6 and $24 \mathrm{~h}$ reperfusion. ROS production was measured by flow cytometry assay at the same time points. Results. In both hypothermia groups, the cerebral infarct volumes and neurological deficits were reduced in the ischemic rats. At 6 and $24 \mathrm{~h}$ reperfusion, ROS production and the expressions of NOX subunits and glucose transporter subtypes were also significantly reduced in both hypothermia groups as compared to the ischemic group. While there were no statistically significant differences between the two hypothermia groups at $6 \mathrm{~h}$ reperfusion, brain damage was significantly further decreased by interischemia hypothermia at $24 \mathrm{~h}$. Conclusion. Both interischemia and inter-reperfusion pharmacological hypothermia treatments play a role in neuroprotection after stroke. Interischemia hypothermia treatment may be better able to induce stronger neuroprotection after ischemic stroke. This study provides a new avenue and reference for stronger neuroprotective hypothermia before vascular recanalization in stroke patients.
\end{abstract}

\section{Introduction}

Stroke is a leading cause of severe disability and a serious threat to human health worldwide. It has caused serious social and economic burdens $[1,2]$. Super-early (4.5 hours) rt-PA intravenous thrombolysis is currently the most commonly used method of treatment for acute cerebral infarction. However, because of the narrow "time window," high bleeding risk, inadequate national health consciousness, poor medical resource distribution, and problematic traffic congestion in our country, the actual thrombolysis rate is less than $30 \%$ [3]. Because of these limitations, a majority of patients cannot get timely and effective treatment [4]. Intra-arterial contact thrombolysis, mechanical thrombolysis, direct stent implantation, and other technologies have gradually appeared in recent years, hence extending the treatment time window and enabling the recanalization rate of occluded vessels to reach $71 \%$ [5-7]. However, the favorable prognosis in patients with recanalization was still less than $46 \%$.

The core principle of acute ischemic cerebral infarction treatment is twofold: to prevent the expansion of irreversible 
injury and to save reversible ischemic tissue (also known as ischemic penumbra) [8]. Hypothermia therapy is currently recognized as one of the few effective neuroprotective strategies in the world [9-14]. In fact, due to its positive neuroprotective effects, mild hypothermia has been used worldwide for brain protection after neonatal hypoxic ischemic encephalopathy $[15,16]$, traumatic brain injury $[17,18]$, and cardiac resuscitation [19]. Clinically, the major limitations of physical hypothermia are the delays in cooling initiation and onset of target temperature. The late start necessitates prolonged cooling duration, which requires extensive medical and nursing efforts, and causes secondary complications [20]. Considering interischemia hypothermia, its benefits have been shown in cardiac studies, where it has improved the prognosis of patients [21]. However, it is not known whether interischemia hypothermia reduces tissue damage in acute ischemic stroke.

Studies have shown that therapeutic hypothermia can play a neuroprotective role by inhibiting the activity of nicotinamide adenine dinucleotide phosphate (NADPH) oxidase (NOX) and reducing the generation of reactive oxygen species (ROS) [22, 23]. NOX activation is an important mechanism of brain injury, which can be further aggravated by high glucose metabolism after stroke. After the occurrence of ischemic stroke, ATP in the penumbra is rapidly exhausted, and the brain tissue produces a large amount of reduced NADPH through the anoxic metabolic pathway through the hexose phosphate bypass. Under the action of NOX, a large amount of ROS is produced, leading to oxidative stress injury [24-26]. Previous studies have proved that NOX gene knockout mice [27] or NOX inhibitor intervention [28] can successfully inhibit ROS production and thereby reduce the oxidative stress injury after ischemia $[29,30]$. In addition, our previous studies have found that drug-induced hypothermia after reperfusion inhibited the activity of NOX, reduced the production of ROS, and reduced the consequent oxidative stress, so as to play a neuroprotective role [31].

In this study, we determined whether interischemia hypothermia induced by the pharmacological approach induced stronger neuroprotection in the brain through inhibiting the activity of NOX and reducing the production of ROS. If successful, this study on the treatment of acute cerebral infarction before recanalization provides a reference for effective treatments and provides a basis for clinical transformation. In this way, stroke patients could receive drug hypothermia treatment with less medical and nursing efforts before vascular recanalization to protect the brain from further injury.

\section{Materials and Methods}

2.1. Subjects. All experimental protocols were approved by the Animal Care and Use Committee, Capital Medical University, Beijing, China, according to the National Institutes of Health (NIH, Bethesda, MD, USA) Guide for the Care and Use of Laboratory Animals. All adult male Sprague Dawley rats (280-320 g, Vital River Laboratory Animal Technology Co., Ltd., Beijing, China) were randomly divided into 4 groups (Figure 1(a)): (1) sham-operated group without middle cerebral artery occlusion (MCAO); (2) stroke group without pharmacological hypothermia (MCAO $2 \mathrm{~h}$ ); (3) stroke group treated with pharmacological hypothermia $1 \mathrm{~h}$ before reperfusion (interischemia hypothermia) (MCAO $2 \mathrm{~h} / 1 \mathrm{~h}$ ); and (4) stroke group treated with pharmacological hypothermia after reperfusion is initiated (inter-reperfusion hypothermia) (MCAO 2h/2h). Each group was further divided into three subgroups, with 8 rats in each subgroup. The combination of chlorpromazine and promethazine with dihydrocapsaicin (DHC) was used to induce hypothermia. All experimental procedures and data analysis were performed in a randomized and blinded manner. At $24 \mathrm{~h}$ reperfusion, neurological deficits and infarct volume were examined in each group, and biochemical assays were performed.

2.2. Focal Cerebral Ischemia. The procedures have been described previously by us [31]. The animals underwent fasting for $12 \mathrm{~h}$ before the operation began. Animals were anesthetized in a chamber with 1-3\% isoflurane along with a mixture of $70 \%$ nitrous oxide and $30 \%$ oxygen and maintained with $1 \%$ isoflurane. A $2 \mathrm{~h}$ right MCAO was induced using an intraluminal filament [32]. During operation, body temperature (rectal temperature), blood $\mathrm{pH}, \mathrm{pCO}_{2}$ and $\mathrm{pO}_{2}$, and mean arterial pressure (MAP) were all monitored. Laser Doppler was used to monitor blood flow in the MCAsupplied region to ensure the success of the model.

2.3. Pharmacological Hypothermia. In all ischemia models with $2 \mathrm{~h}$ MCAO following reperfusion, a $1: 1$ ratio of chlorpromazine and promethazine $(\mathrm{C}+\mathrm{P})$ at $4 \mathrm{mg} / \mathrm{kg}$ in $3 \mathrm{ml}$ of saline combined with dihydrocapsaicin (DHC) at doses of $0.5 \mathrm{mg} / \mathrm{kg}$ [33] was injected intraperitoneally, as described by us previously [31] at 1 or $2 \mathrm{~h}$ after the onset of ischemia. In order to maintain and enhance the efficacy of the drugs, a second injection with $1 / 3$ of the initial dose was delivered in $2 \mathrm{~h}$.

2.4. Body Temperature Monitoring. Rectal temperature (body temperature) was monitored in 30-minute or $1 \mathrm{~h}$ increments from before hypothermia until it returned to the initial levels.

2.5. Cerebral Infarct Volume. The rats were anesthetized with $1 \%$ chloral hydrate, and the brain tissue of the ischemic rats was removed and immediately sliced into seven coronal sections ( $2 \mathrm{~mm}$ thick), as described previously by us [34]. The sections were stained with 2,3,5-triphenyltetrazolium chloride (TTC, Sigma, USA) at $37^{\circ} \mathrm{C}$. Image image analysis software was used to measure cerebral infarction volume. In order to reduce the error caused by cerebral edema, the cerebral infarction volume was measured indirectly using the indirect calculation method, relative to the noninfarcted hemisphere. 


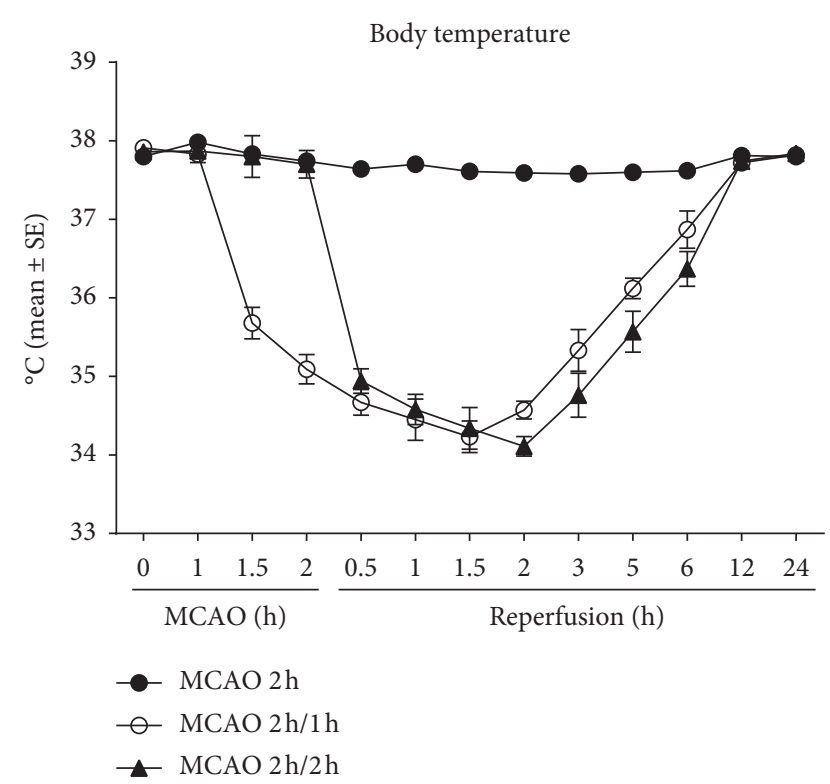

FIgURE 1: Body temperatures of $2 \mathrm{~h}$ MCAO rats with or without hypothermia at different time points.

2.6. Neurological Deficits. The neurological function deficits were determined by the 5-scoring system [32] before surgery, $2 \mathrm{~h}$ after stroke, and $24 \mathrm{~h}$ after reperfusion. The higher scores indicate more serious neurological defects.

2.7. ROS Production Measurement by Flow Cytometry Assay. As described previously by us [35], the adult brain dissociation kit (130-107-677, Miltenyi Biotec, Bergisch Gladbach, Germany) was used for brain cell isolation. Rats were sacrificed at 6 and $24 \mathrm{~h}$ after reperfusion, and the right hemispheres were cut into small pieces, ground, and filtered through a $70 \mu \mathrm{m}$ cell strainer (Miltenyi Biotec, Bergisch Gladbach, Germany) to obtain single-cell suspensions. Fluorescent-labeled antibodies were added to the cells and incubated at $37^{\circ} \mathrm{C}$ for 60 minutes according to the instructions. Cells were then washed and analyzed on a FACSCalibur flow cytometer with CellQuest software (BD, San Jose, CA, USA). Results were expressed by the fluorescence value.

2.8. Expression of NOX Subunits and Glucose Transporter Subtypes. After homogenization of the isolated cerebral microvessels, TRIzol reagent (Invitrogen, Carlsbad, CA) was used to extract mRNA according to the instructions. Total RNA was then converted into cDNA by a High-Capacity cDNA Reverse Transcription Kit (Applied Biosystems, Foster City, CA). Using cDNA, gene expression was quantified by Prism 7500 real-time PCR (Applied Biosystems, CA, USA). All reactions were performed under the following conditions: $95^{\circ} \mathrm{C}$ for 15 minutes, 40 cycles of $95^{\circ} \mathrm{C}$ for 10 seconds, and $60^{\circ} \mathrm{C}$ for 30 seconds. The sequences for the primers of rat NOX subunits $\left(\mathrm{gp} 91^{\text {phox }}, \mathrm{p} 67^{\text {phox }}, \mathrm{p} 47^{\text {phox }}\right.$, and $\mathrm{p} 22^{\mathrm{phox}}$ ), glucose transporter subtypes (GLUT1 and GLUT3), and GADPH are shown in Table 1. GADPH was used as the control gene to determine the relative expression of mRNA.

2.9. Statistical Analyses. All data are expressed as mean \pm SE. All of the analyses were performed using GraphPad Prism v7.0 (GraphPad Software, San Diego, CA). The differences between the groups were assessed using one-way analysis of variance (ANOVA) with the significance level set at $P<0.05$. Post hoc comparisons between groups were further performed using the least significant difference method.

\section{Results}

3.1. Physiological Parameters. There were no significant differences in blood $\mathrm{pH}, \mathrm{pO}_{2}$, and $\mathrm{pCO}_{2}$ between the groups (data not shown).

3.2. Body Temperature. In the interischemia hypothermia group, a $2.23^{\circ} \mathrm{C}$ drop was seen in the temperature within 30 minutes of drug administration at $1 \mathrm{~h}$ after stroke $(1 \mathrm{~h}$ before reperfusion) and continued to fall to the lowest of $3.68^{\circ} \mathrm{C}$ below the initial temperature at $1.5 \mathrm{~h}$ reperfusion (Figure 1 ). Meanwhile, in the inter-reperfusion hypothermia group, a $2.92^{\circ} \mathrm{C}$ drop was seen within 30 minutes of pharmacological hypothermia induction at $30 \mathrm{~min}$ reperfusion and continued to fall to the lowest of $3.75^{\circ} \mathrm{C}$ under the initial temperature at $2 \mathrm{~h}$ reperfusion. For both groups, the body temperatures remained under the initial measurements for up to $12 \mathrm{~h}$ reperfusion. Notably, hypothermia was achieved $1 \mathrm{~h}$ earlier in the interischemia group compared to the inter-reperfusion hypothermia group.

3.3. Cerebral Infarct Volume and Neurological Deficits. As compared to the stroke group without hypothermia, with the largest cerebral infarct volume at $24 \mathrm{~h}$ reperfusion $(48.5 \%)$ (Figures 2(a) and 2(b)), both hypothermia groups had significantly decreased infarct volumes. The interischemia hypothermia group had a greater decrease in infarct volume of $25.2 \%\left({ }^{\# \#} p<0.001\right)$ vs. $32.1 \%\left({ }^{\# \#} p<0.01\right)$ in the interreperfusion hypothermia group. As compared to the stroke group at $24 \mathrm{~h}$ reperfusion (3.0) (Figure 2(c)), again, both interischemia hypothermia group $(\# \#<0.01)$ and interreperfusion hypothermia group $\left({ }^{\#} p<0.05\right)$ had reduced neurological deficit scores, with interischemia hypothermia being more neuroprotective.

3.4. Expression of NOX Subunits and Glucose Transporter Subtypes. The stroke group without hypothermia had a significant increase in the mRNA expression of NOX subunits $\left(\mathrm{gp} 91^{\text {phox }}, \mathrm{p} 67^{\text {phox }}, \mathrm{p} 47^{\text {phox }}\right.$, and $\left.\mathrm{p} 22^{\text {phox }}\right)$ at 6 and $24 \mathrm{~h}$ reperfusion (Figure 3 ). Compared to this group, both hypothermia groups observed significantly reduced mRNA expressions of NOX subunits at 6 and $24 \mathrm{~h}$ reperfusion. At $24 \mathrm{~h}$ reperfusion (Figures $3(\mathrm{~b}), 3(\mathrm{~d}), 3(\mathrm{f})$, and $3(\mathrm{~h})$ ), the interischemia hypothermia group had a significant additional reduction in NOX subunit mRNA expression. 
TABLE 1: Primers for real-time polymerase chain reaction (PCR) analysis.

\begin{tabular}{|c|c|c|}
\hline Genes & Forward primer $\left(5^{\prime}-3^{\prime}\right)$ & Reverse primer $\left(5^{\prime}-3^{\prime}\right)$ \\
\hline gp91 ${ }^{\text {phox }}$ & TGACTCGGTTGGCTGGCATC & CGCAAAGGTACAGGAACATGGG \\
\hline p $67^{\text {phox }}$ & AGCAGAAGAGCAGTTAGCATTGG & TGCTTTCCATGGCCTTGTC \\
\hline $\mathrm{p} 47^{\text {phox }}$ & TCACCGAGATCTACGAGTTC & ATCCCATGAGGCTGTTGAAGT \\
\hline $\mathrm{p} 22^{\text {phox }}$ & TGTTGCAGGAGTGCTCATCTGTCT & AGGACAGCCCGGACGTAGTAATTT \\
\hline GLUT1 & CAGAGCGACAAGACACCTGA & ACTGAAGAAAGGTGCCCAGG \\
\hline GLUT3 & GTGGAGCGGTGAAGATCAGATA & GGCAACAGTAACAGCGAACA \\
\hline GADPH & CAAGAAGGTGGTGAAGCAG & AAAGGTGGAAGAATGGGAG \\
\hline
\end{tabular}

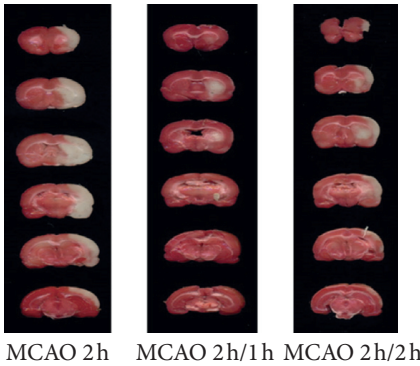

(a)

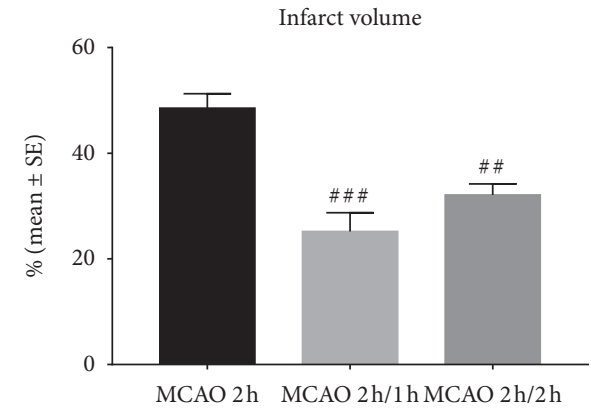

(b)

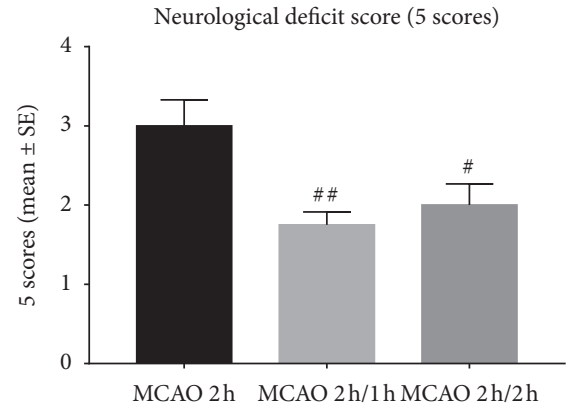

(c)

FIGURE 2: TTC histology demonstrated cerebral infarct volume after stroke with or without hypothermia (a, b). Neurological deficits after stroke and pharmacological hypothermia, using the 5 -score system (c). ${ }^{\#} p<0.05,{ }^{\# \#} p<0.01$, and ${ }^{\# \# \#} p<0.001$ as compared to the MCAO $2 \mathrm{~h}$ group $(n=8)$.

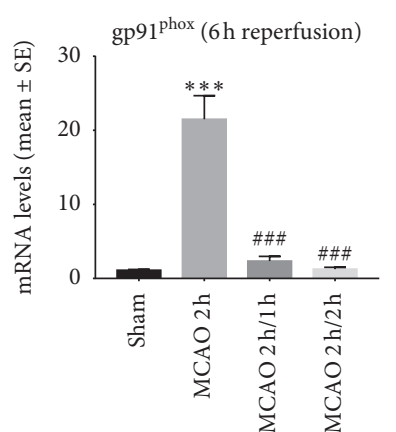

(a)

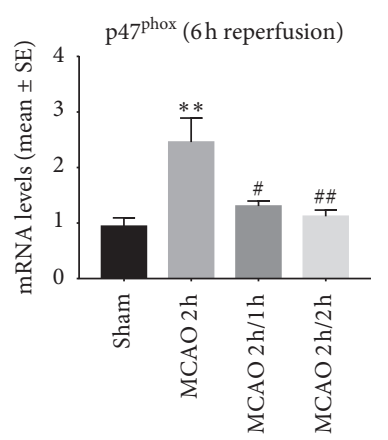

(e)

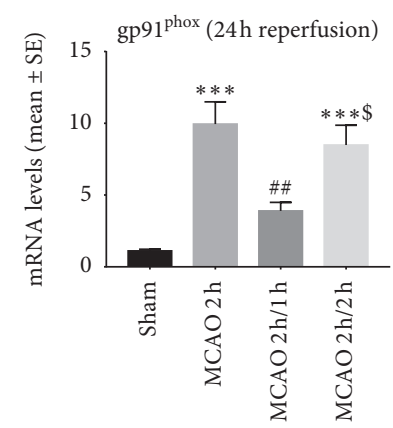

(b)

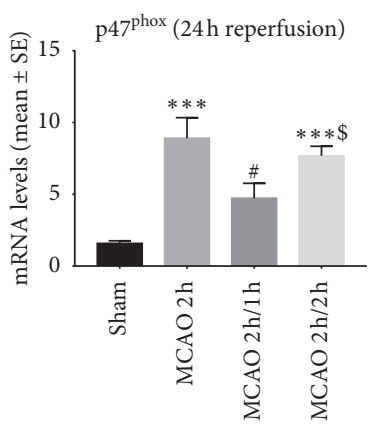

(f)

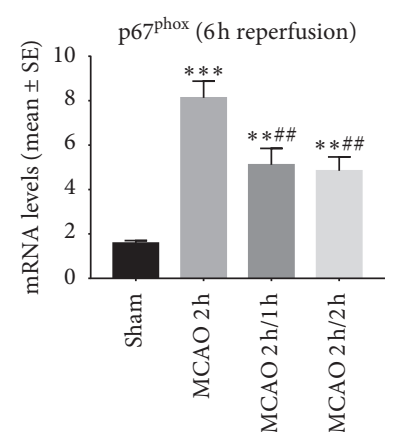

(c)

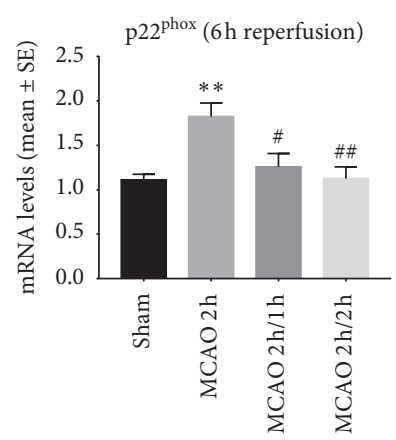

$(\mathrm{g})$

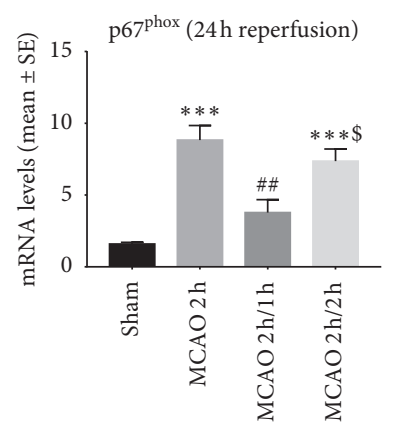

(d)

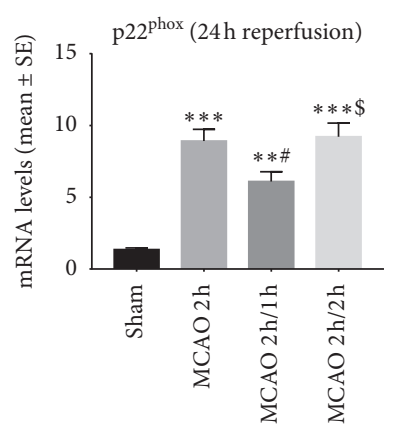

(h)

FIgURE 3: The mRNA expressions of NOX subunits (gp91 ${ }^{\text {phox }}, \mathrm{p} 67^{\text {phox }}, \mathrm{p} 47^{\text {phox }}$, and $\mathrm{p} 22^{\text {phox }}$ ) determined by real-time PCR at 6 and $24 \mathrm{~h}$ reperfusion. ${ }^{*} P<0.05,{ }^{* *} P<0.01$, and ${ }^{* * *} P<0.001$ as compared to the sham group; ${ }^{\#} p<0.05$, \#\# $p<0.01$, and \#\#\# $p<0.001$ as compared to the MCAO $2 \mathrm{~h}$ group; ${ }^{\$} P<0.05$ as compared to the MCAO $2 \mathrm{~h} / 1 \mathrm{~h}$ group $(n=8)$. 
A significant increase in the mRNA expression of glucose transporter subtypes (GLUT1 and GLUT3) was seen in ischemic rats with 6 and $24 \mathrm{~h}$ reperfusion (Figure 4). Both hypothermia groups observed significantly reduced mRNA expressions. Although there was no difference between interischemia and inter-reperfusion in the reduction of glucose transporter subtype mRNA at $6 \mathrm{~h}$ reperfusion (Figures 4(a) and 4(c)), at $24 \mathrm{~h}$ reperfusion (Figures 4(b) and $4(d)$ ), interischemia hypothermia induced a significantly greater reduction of mRNA expression.

3.5. ROS Production. Stroke induced a significant increase in ROS production at 6 and $24 \mathrm{~h}$ reperfusion $\left({ }^{*} P<0.01\right)$ (Figure 5). The two hypothermia protocols significantly decreased the ROS production at $6 \mathrm{~h}$ reperfusion (Figures 5(a) and 5(c)) $\left({ }^{\# \#} p<0.01\right)$, while the interischemia hypothermia group enhanced the ROS reduction $(P \$<0.05)$ at $24 \mathrm{~h}$ reperfusion (Figures $5(\mathrm{~b})$ and $5(\mathrm{~d}))$.

\section{Discussion}

In this study, we reported that hypothermia conducted interischemia or inter-reperfusion reduced cerebral infarction volume, neurological deficits, ROS production, and mRNA expression of NOX subunits as well as glucose transporter subtypes. In addition, we found that interischemia hypothermia had further reduced the indications for brain damage compared to inter-reperfusion hypothermia at $24 \mathrm{~h}$ after stroke. These findings support our hypothesis that interischemia hypothermia induced by the pharmacological approach provided stronger neuroprotection of the ischemic brain.

Hypothermia therapy depends largely on several factors, such as the time of initiation, the duration, and the depth of hypothermia $[11,36]$. Studies have shown that hypothermia should be initiated as soon as possible, target temperature reached quickly, and the lower temperature maintained for a considerable period for better neuroprotective effect [20]. Some earlier studies have shown that reducing the body temperature by only a few degrees, if it is induced in the early ischemic period, can have significant neuroprotective effects [37-39].

The benefits of interischemia hypothermia have been shown in cardiac studies [40,41]. Studies have reported that hypothermia before reperfusion can reduce the size of myocardial infarction, save more dying myocardial cells, and improve the outcome of myocardial infarction. Many studies of animal models and human trials have shown that interischemia hypothermia is not only safe and feasible but also has good protective effects on ischemic myocardium [42-45]. Compared to postreperfusion hypothermia, interischemia hypothermia has been shown to be more beneficial to cardiomyocytes, which may be related to decreased core infarction volume, oxidative damage, and cell damage after reperfusion. To further illustrate, a previous study showed that the induction of hypothermia 25 minutes after ischemia onset with 40 minutes total ischemia time resulted in a 39\% reduction in myocardial infarction area in pigs, whereas hypothermia after reperfusion did not reduce myocardial infarct volume [43]. Furthermore, reaching target temperature before reperfusion is of crucial importance in reducing the infarct size in the treatment of STsegment elevation myocardial infarction (STEMI) patients [46].

In cerebral ischemia, some evidence supports that early prophylactic mild-to-moderate hypothermia induced shortly after injury in patients with severe traumatic brain injury could decrease mortality and improve neurologic recovery [47]. Ding et al. showed that local cerebral hypothermia induced by infusion of cold saline prior to reperfusion that is maintained for 10 minutes and followed by complete reperfusion can reduce brain injury, improve neurological function, and maintain long-term functional recovery [48]. The advantage of interischemia hypothermia is that the target temperature is reached prior to reperfusion, which not only reduces ischemia injury but also reperfusion injury. Therefore, it is more beneficial to start hypothermia treatment as soon as possible after brain injury.

At present, hypothermia therapy in clinical practice is mainly systemic physical cooling or endovascular intracarotid infusion of cold saline [49-52]. It is difficult to establish, slow in cooling, cannot reach the target temperature quickly, and can easily lead to serious complications such as arrhythmias and pulmonary infections [53-55]. Therefore, current clinical application of hypothermia is limited. In contrast, drug hypothermia is more convenient and can achieve the target temperature before vascular recanalization without extensive medical and nursing efforts. This may have a certain clinical application prospect, where it could become a better choice for hypothermia induction before vascular recanalization [11]. However, drug hypothermia also has some limitations. The efficiency of single-drug application is low with many complications. When drugs are combined in low doses, they can build a synergistic effect, improving the efficiency of low temperature, reducing the side effects of any single drug, and minimizing complications. Our previous study demonstrated that chlorpromazine and promethazine $(\mathrm{C}+\mathrm{P})$ significantly reduced the volume of cerebral infarction in rats and attenuated neurological deficit $[31,56]$. Dihydrocapsaicin (DHC), a potential capsaicin channel transient receptor agonist (TRPV1), is also currently being investigated as a promising drug cryogenic inducer $[57,58]$. Studies have shown that DHC in high doses can independently achieve effective hypothermia therapy, although its applications alone are limited due to the significant toxicity and complications $[11,33]$. However, combined with low doses of $C+P$, it might play a synergistic effect, improve the efficiency of hypothermia, reduce the side effects of the single drug, and reduce the complications [59]. Therefore, in this study, we chose $\mathrm{C}+\mathrm{P}$ combined with $\mathrm{DHC}$ to induce pharmacological hypothermia.

The full mechanism of hypothermia's neuroprotective effects is still being explored and described. A review has shown that hypothermia may act on several pathways in the ischemic cascade and have different effects on the inflammatory response at different time points [60]. ROS 


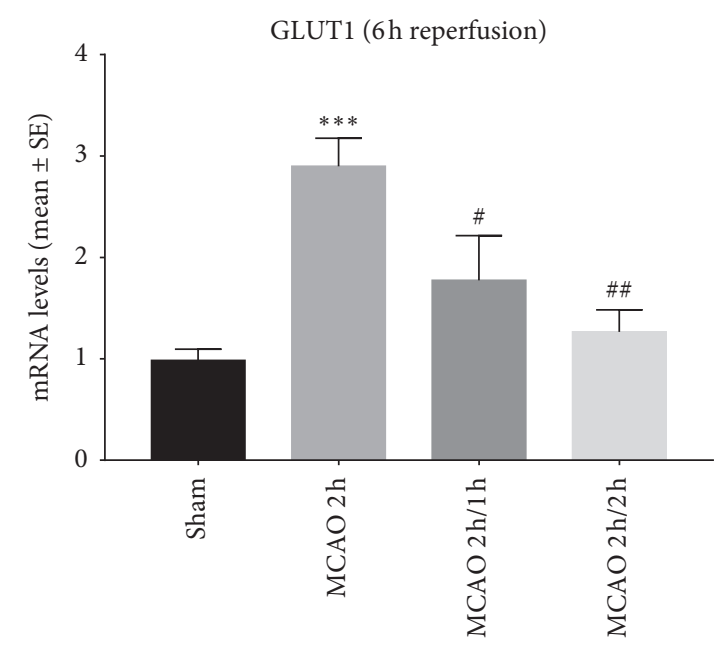

(a)

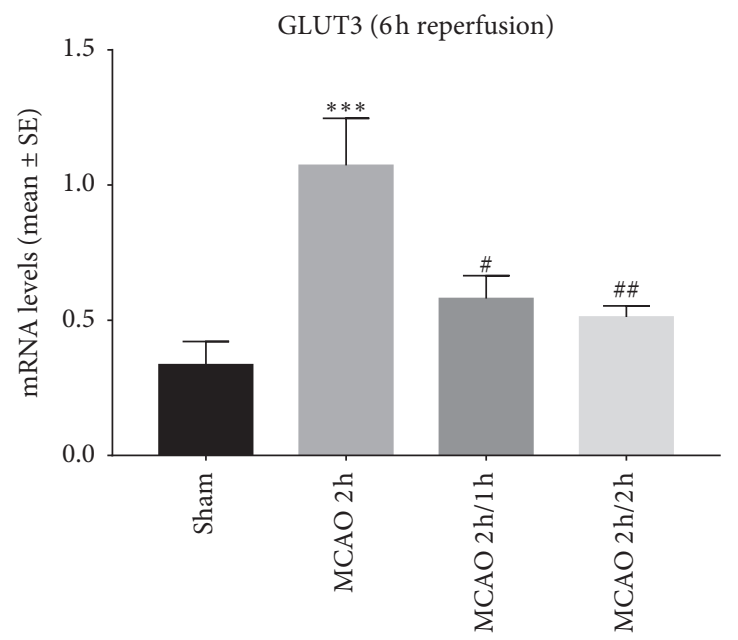

(c)

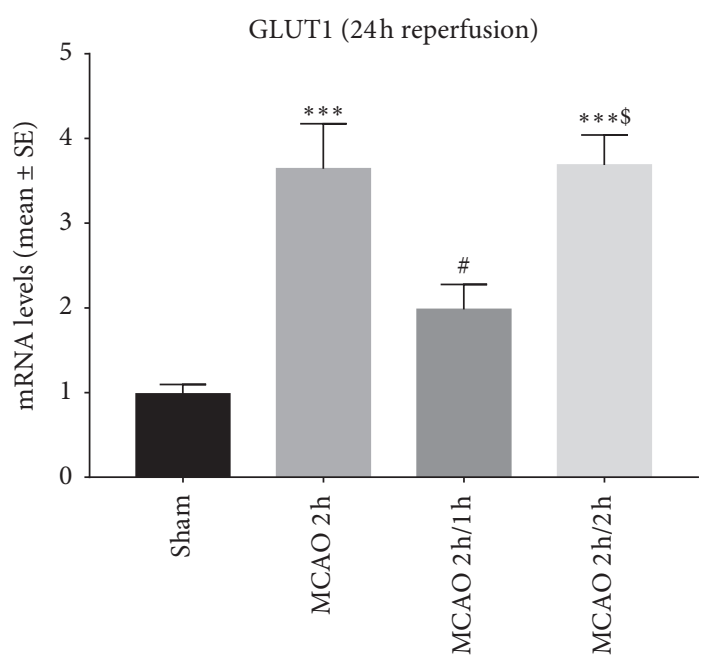

(b)

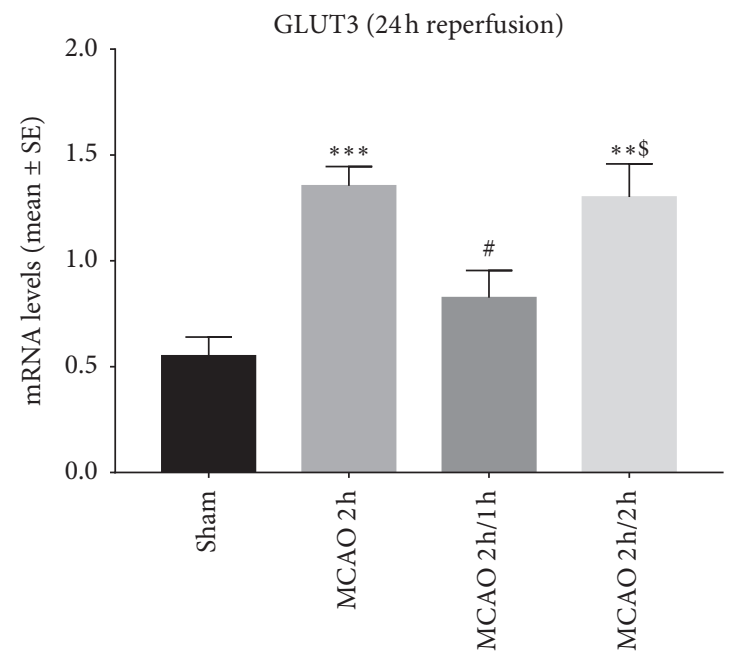

(d)

FIgURE 4: The mRNA expressions of glucose transporter subtypes (GLUT1 and GLUT3) determined by real-time PCR at 6 and $24 \mathrm{~h}$ reperfusion. ${ }^{* *} P<0.01$ and ${ }^{*}{ }^{*} * P<0.001$ as compared to the sham group; ${ }^{*} p<0.05$ and ${ }^{\# \#} p<0.01$ as compared to the MCAO $2 \mathrm{~h}$ group; $\$ P<0.05$ as compared to the MCAO $2 \mathrm{~h} / 1 \mathrm{~h}$ group $(n=8)$.

plays an important role in the pathophysiological process of ischemic neuron injury [23]. NADPH oxidase complex produces superoxide $\left(\mathrm{O}_{2}\right)$ and is involved in ROS production during ischemia and reperfusion [61]. Explosive ROS production has been shown to occur mainly in the first 10-15 minutes of reperfusion in the MCAO rat model [22]. In this model, our study shows that interischemia hypothermia and inter-reperfusion hypothermia induced by both low doses of phenothiazine drugs and DHC reduced ischemia-reperfusion injury, protected brain tissue, and induced neuroprotection compared to stroke without treatment. Interischemia hypothermia treatment may be better able to induce stronger neuroprotection after stroke. 


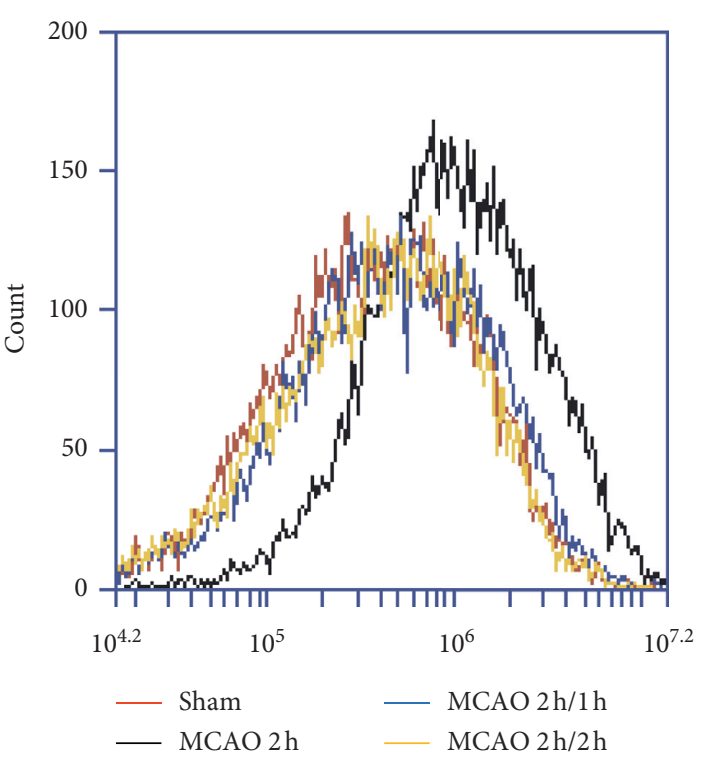

(a)

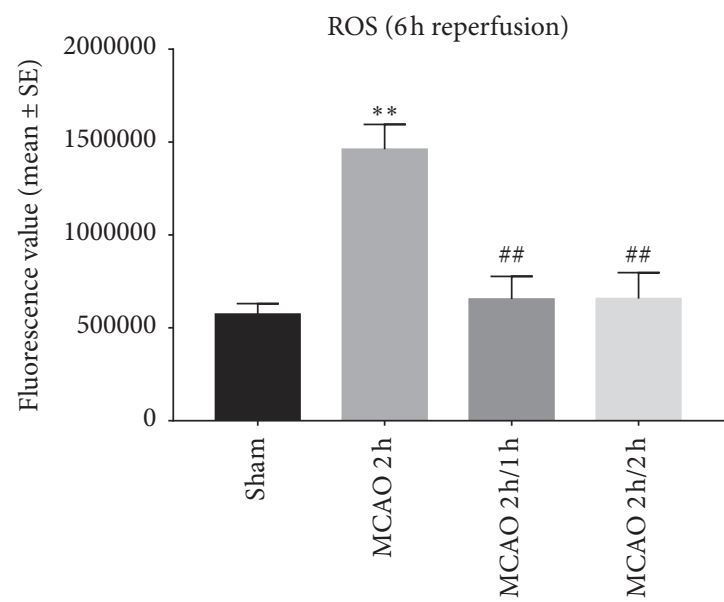

(c)

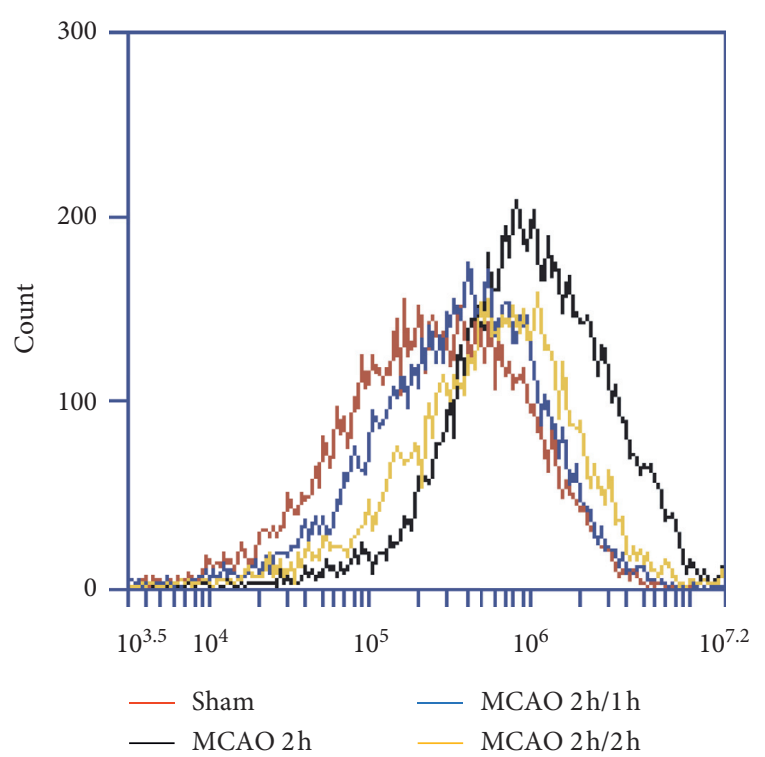

(b)

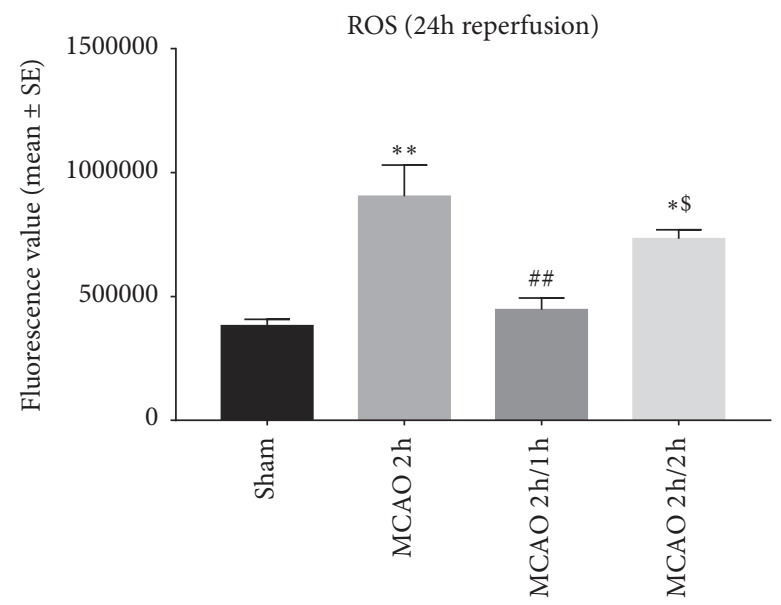

(d)

Figure 5: ROS production by flow cytometry assay. ${ }^{*} P<0.05$ and ${ }^{* *} P<0.01$ as compared to the sham group; ${ }^{\#} p<0.05$ and ${ }^{\# \#} p<0.01$ as compared to the MCAO $2 \mathrm{~h}$ group; ${ }^{\$} P<0.05$ as compared to the MCAO $2 \mathrm{~h} / 1 \mathrm{~h}$ group $(n=8)$. The $x$-axis is the fluorescence value. Red: sham; black: MCAO $2 \mathrm{~h}$; blue: MCAO $2 \mathrm{~h} / 1 \mathrm{~h}$; yellow: MCAO $2 \mathrm{~h} / 2 \mathrm{~h}$.

\section{Conclusion}

In conclusion, both interischemia and inter-reperfusion pharmacological hypothermia treatments play a role in neuroprotection after stroke. Interischemia hypothermia treatment may be better able to induce stronger neuroprotection after ischemic stroke. In the current clinical environment, delaying reperfusion therapy to wait for hypothermia induction is not feasible. Fortunately, pharmacological hypothermia with low dose is quick and easy to use and has few side effects when used in combination. Patients could be cooled upon arrival to the emergency room or even prior to, perhaps in the ambulance by Emergency Medical Services (EMS), en route to the primary or advanced stroke unit, before thrombolysis or thrombectomy. This study provides a referential and effective treatment strategy for cerebral protection before vascular recanalization in acute ischemic stroke, as well as the basis for the realization of clinical transformation.

\section{Data Availability}

The original data used to support the findings of this study are included within the article.

\section{Disclosure}

Part of this study was presented as a poster in Medical Student Research Symposium at Wayne State University, School of Medicine.

\section{Conflicts of Interest}

The authors declare no conflicts of interest. 


\section{Authors' Contributions}

Yun Han designed the study, performed the research, analyzed the data, and wrote the paper. Hangil Lee edited the paper and polished the language. Fengwu Li conceived the study, analyzed the data, and edited the paper. Xiaokun Geng conceived and designed the study and reviewed the paper. Yuchuan Ding designed the study and reviewed the paper. All authors read and approved the final manuscript.

\section{Acknowledgments}

This work was partially supported by the National Nature Science Foundation of China (nos. 81871838 and 81802231), Beijing Tongzhou District Financial Fund, and the Science and Technology Plan of Beijing Tongzhou District (KJ2018CX006).

\section{References}

[1] J. Minnerup, B. A. Sutherland, A. M. Buchan, and C. Kleinschnitz, "Neuroprotection for stroke: current status and future perspectives," International Journal of Molecular Sciences, vol. 13, no. 9, pp. 11753-11772, 2012.

[2] S. Wu, B. Wu, M. Liu et al., "Stroke in China: advances and challenges in epidemiology, prevention, and management," The Lancet Neurology, vol. 18, no. 4, pp. 394-405, 2007.

[3] T. Knecht, C. Borlongan, and I. Dela Pena, "Combination therapy for ischemic stroke: novel approaches to lengthen therapeutic window of tissue plasminogen activator," Brain Circulation, vol. 4, no. 3, pp. 99-108, 2018.

[4] R. Kollmar and S. Schwab, "Hypothermia and ischemic stroke," Current Treatment Options in Neurology, vol. 14, no. 2, pp. 188-196, 2012.

[5] M. Goyal, B. K. Menon, W. H. van Zwam et al., "Endovascular thrombectomy after large-vessel ischaemic stroke: a metaanalysis of individual patient data from five randomised trials," The Lancet, vol. 387, no. 10029, pp. 1723-1731, 2016.

[6] R. G. Nogueira, A. P. Jadhav, D. C. Haussen et al., "Thrombectomy 6 to 24 hours after stroke with a mismatch between deficit and infarct," New England Journal of Medicine, vol. 378, no. 1, pp. 11-21, 2018.

[7] G. W. Albers, M. P. Marks, S. Kemp et al., "Thrombectomy for stroke at 6 to 16 hours with selection by perfusion imaging," New England Journal of Medicine, vol. 378, no. 8, pp. 708-718, 2018.

[8] M. Paciaroni, V. Caso, and G. Agnelli, "The concept of ischemic penumbra in acute stroke and therapeutic opportunities," European Neurology, vol. 61, no. 6, pp. 321-330, 2009.

[9] J. H. Choi and J. Pile-Spellman, "Reperfusion changes after stroke and practical approaches for neuroprotection," Neuroimaging Clinics of North America, vol. 28, no. 4, pp. 663682, 2018.

[10] M. A. Yenari and H. S. Han, "Neuroprotective mechanisms of hypothermia in brain ischaemia," Nature Reviews Neuroscience, vol. 13, no. 4, pp. 267-278, 2012.

[11] M. Zhang, H. Wang, J. Zhao et al., "Drug-induced hypothermia in stroke models: does it always protect?" CNS \& Neurological Disorders - Drug Targets, vol. 12, no. 3, pp. 371-380, 2013.

[12] X. Liu, D. Wu, S. Wen et al., "Mild therapeutic hypothermia protects against cerebral ischemia/reperfusion injury by inhibiting miR-15b expression in rats," Brain Circulation, vol. 3, no. 4, pp. 219-226, 2017.

[13] L. Liu, X. Liu, R. Wang et al., "Mild focal hypothermia regulates the dynamic polarization of microglia after ischemic stroke in mice," Neurological Research, vol. 40, no. 6, pp. 508-515, 2018.

[14] Z. Zhang, L. Zhang, Y. Ding, Z. Han, and X. Ji, "Effects of therapeutic hypothermia combined with other neuroprotective strategies on ischemic stroke: review of evidence," Aging and Disease, vol. 9, no. 3, pp. 507-522, 2018.

[15] S. Shankaran, A. Pappas, S. A. McDonald et al., "Childhood outcomes after hypothermia for neonatal encephalopathy," New England Journal of Medicine, vol. 366, no. 22, pp. 2085-2092, 2012.

[16] L. A. Papile, "Systemic hypothermia--a "cool" therapy for neonatal hypoxic-ischemic encephalopathy," New England Journal of Medicine, vol. 353, no. 15, pp. 1619-1620, 2005.

[17] H. Ma, B. Sinha, R. S. Pandya et al., "Therapeutic hypothermia as a neuroprotective strategy in neonatal hypoxic-ischemic brain injury and traumatic brain injury," Current Molecular Medicine, vol. 12, no. 10, pp. 1282-1296, 2012.

[18] W. D. Dietrich and H. M. Bramlett, "Therapeutic hypothermia and targeted temperature management for traumatic brain injury: experimental and clinical experience," Brain Circulation, vol. 3, no. 4, pp. 186-198, 2017.

[19] G. Hypothermia, "After cardiac arrest study mild therapeutic hypothermia to improve the neurologic outcome after cardiac arrest," New England Journal of Medicine, vol. 346, no. 8, pp. 549-556, 2002.

[20] M. Kohlhauer, A. Berdeaux, B. Ghaleh, and R. Tissier, "Therapeutic hypothermia to protect the heart against acute myocardial infarction," Archives of Cardiovascular Diseases, vol. 109, no. 12, pp. 716-722, 2016.

[21] S. A. Bernard, T. W. Gray, M. D. Buist et al., "Treatment of comatose survivors of out-of-hospital cardiac arrest with induced hypothermia," New England Journal of Medicine, vol. 346, no. 8, pp. 557-563, 2002.

[22] C. M. Maier, G. H. Sun, D. Cheng, M. A. Yenari, P. H. Chan, and G. K. Steinberg, "Effects of mild hypothermia on superoxide anion production, superoxide dismutase expression, and activity following transient focal cerebral ischemia," Neurobiol Dis, vol. 11, no. 1, pp. 28-42, 2002.

[23] T. Horiguchi, K. Shimizu, M. Ogino, S. Suga, J. Inamasu, and T. Kawase, "Postischemic hypothermia inhibits the generation of hydroxyl radical following transient forebrain ischemia in rats," Journal of Neurotrauma, vol. 20, no. 5, pp. 511-520, 2003.

[24] A. Y. Abramov, A. Scorziello, and M. R. Duchen, "Three distinct mechanisms generate oxygen free radicals in neurons and contribute to cell death during anoxia and reoxygenation," Journal of Neuroscience, vol. 27, no. 5, pp. 1129-1138, 2007.

[25] S. Manzanero, T. Santro, and T. V. Arumugam, "Neuronal oxidative stress in acute ischemic stroke: sources and contribution to cell injury," Neurochemistry International, vol. 62, no. 5, pp. 712-718, 2013.

[26] J. Shen, R. Rastogi, L. Guan et al., "Omega-3 fatty acid supplement reduces activation of NADPH oxidase in intracranial atherosclerosis stenosis," Neurological Research, vol. 40, no. 6, pp. 499-507, 2018.

[27] H. Chen, Y. S. Song, and P. H. Chan, "Inhibition of NADPH oxidase is neuroprotective after ischemia-reperfusion," Journal of Cerebral Blood Flow \& Metabolism, vol. 29, no. 7, pp. 1262-1272, 2009. 
[28] J. Shen, X. Y. Bai, Y. Qin et al., "Interrupted reperfusion reduces the activation of NADPH oxidase after cerebral I/R injury," Free Radical Biology and Medicine, vol. 50, no. 12, pp. 1780-1786, 2011.

[29] T. Kahles and R. P. Brandes, "NADPH oxidases as therapeutic targets in ischemic stroke," Cellular and Molecular Life Sciences, vol. 69, no. 14, pp. 2345-2363, 2012.

[30] B. Cairns, J. Y. Kim, X. N. Tang, and M. A. Yenari, "NOX inhibitors as a therapeutic strategy for stroke and neurodegenerative disease," Current Drug Targets, vol. 13, no. 2, pp. 199-206, 2012.

[31] X. Geng, F. Li, J. Yip et al., "Neuroprotection by chlorpromazine and promethazine in severe transient and permanent ischemic stroke," Molecular Neurobiology, vol. 54, no. 10, pp. 8140-8150, 2017.

[32] E. Z. Longa, P. R. Weinstein, S. Carlson, and R. Cummins, "Reversible middle cerebral artery occlusion without craniectomy in rats," Stroke, vol. 20, no. 1, pp. 84-91, 1989.

[33] J. Zhang, K. Liu, O. Elmadhoun et al., "Synergistically induced hypothermia and enhanced neuroprotection by pharmacological and physical approaches in stroke," Aging and Disease, vol. 9, no. 4, pp. 578-589, 2018.

[34] X. Geng, O. Elmadhoun, C. Peng et al., "Ethanol and normobaric oxygen: novel approach in modulating pyruvate dehydrogenase complex after severe transient and permanent ischemic stroke," Stroke, vol. 46, no. 2, pp. 492-499, 2015.

[35] C. Chen, W. Jiang, Z. Liu et al., "Splenic responses play an important role in remote ischemic preconditioning-mediated neuroprotection against stroke," Journal of Neuroinflammation, vol. 15, no. 1, p. 167, 2018.

[36] V. Feigin, N. Anderson, A. Gunn, A. Rodgers, and C. Anderson, "The emerging role of therapeutic hypothermia in acute stroke," The Lancet Neurology, vol. 2, no. 9, p. 529, 2003.

[37] R. Busto, W. D. Dietrich, M. Y. Globus, I. Valdes, P. Scheinberg, and M. D. Ginsberg, "Small differences in intraischemic brain temperature critically determine the extent of ischemic neuronal injury," Journal of Cerebral Blood Flow \& Metabolism, vol. 7, no. 6, pp. 729-738, 1987.

[38] M. D. Ginsberg, L. L. Sternau, M. Y. Globus, W. D. Dietrich, and R. Busto, "Therapeutic modulation of brain temperature: relevance to ischemic brain injury," Neurobiology of Ischemic Brain Damage,Progress in Brain Research, vol. 4, no. 3, pp. 189-225, 1993.

[39] T. Miki, G. S. Liu, M. V. Cohen, and J. M. Downey, "Mild hypothermia reduces infarct size in the beating rabbit heart: a practical intervention for acute myocardial infarction?" Basic Research in Cardiology, vol. 93, no. 5, pp. 372-383, 1998.

[40] S. R. Dixon, R. J. Whitbourn, M. W. Dae et al., "Induction of mild systemic hypothermia with endovascular cooling during primary percutaneous coronary intervention for acute myocardial infarction," ACC Current Journal Review, vol. 40, no. 11, pp. 1928-1934, 2003.

[41] D. Stub, S. Bernard, V. Pellegrino et al., "Refractory cardiac arrest treated with mechanical CPR, hypothermia, ECMO and early reperfusion (the CHEER trial)," Resuscitation, vol. 86, pp. 88-94, 2015.

[42] L. Darbera, M. Chenoune, F. Lidouren et al., "Hypothermic liquid ventilation prevents early hemodynamic dysfunction and cardiovascular mortality after coronary artery occlusion complicated by cardiac arrest in rabbits," Critical Care Medicine, vol. 41, no. 12, pp. e457-465, 2013.

[43] M. Gotberg, G. K. Olivecrona, H. Engblom et al., "Rapid short-duration hypothermia with cold saline and endovascular cooling before reperfusion reduces microvascular obstruction and myocardial infarct size," BMC Cardiovascular Disorders, vol. 8, p. 7, 2008.

[44] M. Gotberg, G. K. Olivecrona, S. Koul et al., "A pilot study of rapid cooling by cold saline and endovascular cooling before reperfusion in patients with ST-elevation myocardial infarction," Circulation: Cardiovascular Interventions, vol. 3, no. 5, pp. 400-407, 2010.

[45] H. Hamamoto, H. Sakamoto, B. G. Leshnower et al., "Very mild hypothermia during ischemia and reperfusion improves postinfarction ventricular remodeling," The Annals of Thoracic Surgery, vol. 87, no. 1, pp. 172-177, 2009.

[46] D. Erlinge, "A review of mild hypothermia as an adjunctive treatment for ST-elevation myocardial infarction," Therapeutic Hypothermia and Temperature Management, vol. 1, no. 3, pp. 129-141, 2011.

[47] J. L. Fox, E. N. Vu, M. Doyle-Waters, J. R. Brubacher, R. AbuLaban, and Z. Hu, "Prophylactic hypothermia for traumatic brain injury: a quantitative systematic review," CJEM, vol. 12, no. 4, pp. 355-364, 2010.

[48] Y. Ding, J. Li, X. Luan et al., "Local saline infusion into ischemic territory induces regional brain cooling and neuroprotection in rats with transient middle cerebral artery occlusion," Neurosurgery, vol. 54, no. 4, pp. 956-964, 2004.

[49] J. Caroff, R. M. King, J. E. Mitchell et al., "Focal cooling of brain parenchyma in a transient large vessel occlusion model: proof-of-concept," Journal of NeuroInterventional Surgery, vol. 12, 2020.

[50] S. A. Bernard, K. Smith, J. Finn et al., "Induction of therapeutic hypothermia during out-of-hospital cardiac arrest using a rapid infusion of cold saline: the RINSE trial (rapid infusion of cold normal saline)," Circulation, vol. 134, no. 11, pp. 797-805, 2016.

[51] D. Erlinge, M. Gotberg, I. Lang et al., "Rapid endovascular catheter core cooling combined with cold saline as an adjunct to percutaneous coronary intervention for the treatment of acute myocardial infarction. The CHILL-MI trial: a randomized controlled study of the use of central venous catheter core cooling combined with cold saline as an adjunct to percutaneous coronary intervention for the treatment of acute myocardial infarction," Journal of the American College of Cardiology, vol. 63, no. 18, pp. 1857-1865, 2014.

[52] J. H. Choi, R. S. Marshall, M. A. Neimark et al., "Selective brain cooling with endovascular intracarotid infusion of cold saline: a pilot feasibility study," American Journal of Neuroradiology, vol. 31, no. 5, pp. 928-934, 2010.

[53] S. Liu and J. F. Chen, "Strategies for therapeutic hypometabothermia," Journal of Experimental Stroke \& Translational Medicine, vol. 5, no. 1, pp. 31-42, 2012.

[54] M. Yenari and J. Kim, "Hypothermia for treatment of stroke," Brain Circulation, vol. 11 page, 2015.

[55] K. H. Polderman, "Mechanisms of action, physiological effects, and complications of hypothermia," Critical Care Medicine, vol. 37, no. 7, pp. S186-S202, 2009.

[56] M. V. Narayanan, W. Zhang, I. G. Stavrovskaya, B. S. Kristal, and R. M. Friedlander, "Promethazine: a novel application as a neuroprotectant that reduces ischemia-mediated injury by inhibiting mitochondrial dysfunction," Clinical Neurology and Neurosurgery, vol. 51, pp. 102-107, 2008.

[57] Z. Cao, A. Balasubramanian, and S. P. Marrelli, "Pharmacologically induced hypothermia via TRPV1 channel agonism provides neuroprotection following ischemic stroke when initiated 90 min after reperfusion," American Journal of 
Physiology-Regulatory, Integrative and Comparative Physiology, vol. 306, no. 2, pp. R149-R156, 2014.

[58] K. Fosgerau, U. J. Weber, J. W. Gotfredsen et al., "Druginduced mild therapeutic hypothermia obtained by administration of a transient receptor potential vanilloid type 1 agonist," BMC Cardiovascular Disorders, vol. 10, p. 51, 2010.

[59] S. Liu, X. Geng, B. Forreider et al., "Enhanced beneficial effects of mild hypothermia by phenothiazine drugs in stroke therapy," Neurological Research, vol. 37, no. 5, pp. 454-460, 2015.

[60] H. Zhao, G. K. Steinberg, and R. M. Sapolsky, "General versus specific actions of mild-moderate hypothermia in attenuating cerebral ischemic damage," Journal of Cerebral Blood Flow \& Metabolism, vol. 27, no. 12, pp. 1879-1894, 2007.

[61] C. E. Walder, S. P. Green, W. C. Darbonne et al., "Ischemic stroke injury is reduced in mice lacking a functional NADPH oxidase," Stroke, vol. 28, no. 11, pp. 2252-2258, 1997. 